\title{
GESTÃo DE RESÍDUOS SÓLIDOS NO PROCESSO PRODUTIVO: um estudo de caso em uma indústria calçadista
}

\author{
Eliseu Afonso SOARES ${ }^{1}$ \\ Geraldino Carneiro de ARAÚJO² \\ ${ }^{1}$ Graduando em Administração pela UFMS. eliseuaffonso@gmail.com \\ ${ }^{2}$ Administrador, Mestre em Agronegócios, Doutor em Administração e Docente na UFMS. \\ geraldino.araujo@gmail.com
}

Recebido em: 10/11/2015 - Aprovado em: 05/07/2016 - Disponibilizado em: 18/12/2016

\begin{abstract}
RESUMO
Este artigo tem como propósito analisar a gestão de resíduos sólidos industriais no processo produtivo de uma indústria calçadista, analisando os processos de produção, destacando os resíduos mais comuns que são gerados após estes processos e revelar qual é a medida adota pela empresa para diminuir os impactos ambientais. A gestão de resíduos sólidos é constituída por várias ações ou procedimentos que visam reduzir ou eliminar os impactos ambientais provocados pelos resíduos procedentes das diversas atividades econômicas para melhorar a qualidade de vida, de saúde e do bem estar social. Para alcançar o objetivo proposto foi realizada investigação direta por meio de fontes primárias em estudo de caso realizado em uma empresa do setor calçadista instalada no parque industrial no município de Paranaíba-MS, utilizando abordagem de pesquisa qualitativa e coleta de dados através de entrevista, observação e análise em documentos. Conclui-se que a empresa onde o estudo foi realizado está ciente dos possíveis danos que ela pode causar ao meio ambiente e para minimizá-los adota algumas medidas que estão contribuindo para a preservação do ambiente natural. No entanto, devido à falta de um aterro sanitário local, a destinação correta destes resíduos nem sempre é efetiva.
\end{abstract}

Palavras chave: Resíduos Sólidos. Indústria Calçadista. Meio Ambiente.

\section{SOLID WASTE MANAGEMENT IN PRODUCTION PROCESS : a case study in a footwear industry}

\begin{abstract}
This article is so intent to analyze the management of industrial solid debris in the manufacturing process of a footwear industry, analyzing the production processes, highlighting the debris more common than is generated after those lawsuits and to reveal what is the measure adopted for the company to slow the environmental impacts. The management of solid waste is constituted by some action or procedures that aim at reduce or eliminate the environmental impacts provoked by the debris to several originating economic activities to improve the quality of life, health and social welfare. To reach the goal you proposed was held investigation straight through primary sources in case study held in a company in the sector footwear installed in the industrial park in the city of Paranaíba-MS, using approach to investigate qualitative and collect data interview, through observation and analysis on the documents. One that concludes the company where the study was accomplished is aware of the possible damage that it may cause to the environment and stops to minimize adopts them any steps that are contributing to the preservation of the natural environment. However, due to lack of a local sanitary embankment to correct, the destination of these waste it does not have to be effective.
\end{abstract}

Key-words: Solid Waste. Footwear Industry. Environment. 


\section{Introdução}

Entende-se por resíduos sólidos industriais o que não é utilizado nos processos de produção de uma indústria, estes podem se tornar um problema ambiental devido ao grande volume gerado. Parte dos resíduos gerados na indústria são resultados de falhas durante o processo de produção o que evidencia o mau aproveitamento das matérias primas. Sendo assim, é de extrema importância otimizar a produção para que se gere menos resíduos e conhecer sua classificação quanto aos riscos que podem causar ao meio ambiente.

Os resíduos sólidos gerado na indústria podem ser descartados, reinseridos no processo produtivo ou destinados aos catadores de materiais recicláveis. $\mathrm{O}$ tratamento, a destinação ou o armazenamento inadequado dos resíduos sólidos industriais contribuem para a degradação do meio ambiente, causam riscos à saúde e prejudicam o desenvolvimento da organização, em contrapartida quando estes resíduos são tratados de forma correta trazem benefícios, geram lucros e propiciam um ambiente mais sustentável, além de contribuir positivamente para a imagem da organização.

Este estudo tem como objetivo analisar a gestão dos resíduos sólidos gerados no processo produtivo de uma indústria calçadista. No setor calçadista nacional existem aproximadamente 8 (oito) mil empresas que empregam diretamente $353 \mathrm{mil}$ pessoas que produzem cerca de 900 milhões de pares de calçados por ano (ABICALÇADOS, 2015).

Neste sentido, considerando o plano da gestão ambiental, é elevado o volume de resíduos derivados da atividade produtiva na indústria calçadista (FRACASSO; VIEGAS, 1998). A alta quantidade de resíduos que sobram dos processos produtivos tornou-se o maior problema ambiental enfrentado pelo setor, juntas estas indústrias geram cerca de 300 toneladas/dia destes resíduos, sendo que grande parte são retalhos de couro que não são recicláveis ou reutilizáveis tornando o reaproveitamento uma alternativa amparada por proteção ambiental. Os sais de cromo utilizados nos curtumes para garantir resistência, flexibilidade e maciez do couro utilizado por estas indústrias calçadistas tornam a classificação destes em classe I considerados perigosos pela legislação ambiental (FAPESP, 2009).

\section{Gestão de Resíduos Sólidos Industriais: aspectos teóricos}

A produção de resíduos industriais se constitui como uma das principais formas de degradação do meio ambiente (BALDIN; ORTH; ZANOTELLI, 2014). Desta forma, o adequado gerenciamento dos resíduos sólidos considerando a redução na geração e a conversão em matéria-prima, coopera na redução dos custos de operação (COELHO et al, 2011). 
O aumento do consumo por parte da sociedade eleva a produção na indústria que por sua vez pela falta de eficiência nos processos produtivos aumentam a geração de resíduos acarretando um desequilibro ambiental, pois, a absorção total destes resíduos torna-se uma tarefa quase que impossível para a natureza, afetando de forma negativa a vida no planeta. Para evitar este desequilibro, as indústrias devem reagir de forma positiva quanto à redução da geração destes resíduos diminuindo os impactos ambientais. Para tentar solucionar este problema é preciso além de um planejamento estratégico, uma gestão integrada que contenha diagnósticos participativos, integração de políticas setoriais, parceria entre setor público e privado, compartilhamento de ações, monitoramento e escolha de tecnologias apropriadas, pois a responsabilidade quanto ao tratamento destes resíduos é de quem gera, devendo esta encontrar a melhor solução e que seja ambientalmente aceita (LIMA, 2009).

Resíduos sólidos industriais são sobras de matérias primas que após as diversas atividades e processos desenvolvidos na indústria não são mais utilizados. Possuem múltiplas características, pois depende do que esta sendo produzido. A Associação Brasileira de Normas Técnicas (ABNT), especificamente a NBR 10.004/2004, classifica os resíduos de acordo com suas propriedades, distinguindo-os em Resíduos Classe I: perigosos; Resíduos Classe II: não perigosos; Resíduos Classe IIA: não inertes e Resíduos Classe IIB: inertes (SUZUKI, 2009).

$\mathrm{O}$ aumento da atividade industrial e a falta de programas eficazes de gestão de resíduos acarretam na sobrecarga de resíduos que não são devidamente reutilizados comprometendo a qualidade de vida de gerações futuras. Esta insustentabilidade e a imputabilidade constituem-se em grandes problemas para a sociedade contemporânea, pois, grande parte destes resíduos afeta negativamente o meio ambiente visto que contém elementos que prejudicam a saúde humana e ainda podem contaminar o solo e os lençóis freáticos (RIBEIRO; MORELLI, 2009).

As indústrias são consideradas as principais responsáveis pela degradação do meio ambiente, pois são poucas as que se preocupam com os problemas ambientais que causam principalmente no que diz respeito à gestão de resíduos. O pressuposto de que as indústrias degradam o meio ambiente, aumenta de forma significativa, pois são poucas as empresas que se preocupam em mudar seus processos produtivos para torná-los mais eficientes ecologicamente, e quando mudam é porque se deparam com as exigências prescritas em lei que implica pena aos que a descumprem do que por preocupação com o ambiente social. O que não se pode negar é que há uma dependência de atitudes tomadas por estas forças produtivas para avançar rumo ao desenvolvimento sustentável (DIAS, 2007). 
Para que os resíduos sólidos sejam usados ou dispensados pelas indústrias de forma correta, devem seguir alguns procedimentos até a sua destinação final, seguindo uma ordem de precedência, minimização da geração de resíduos, reutilização, reciclagem e tratamento (COELHO et al, 2011). Além do uso das novas tecnologias, existe também a possibilidade das ações pedagógicas da Educação Ambiental como meio de conscientização quanto à necessidade de redução de resíduos, pois, cada vez se torna mais corriqueiro deparar-se no setor industrial com o desperdício de materiais. (BALDIN; ORTH; ZANOTELLI, 2014).

As empresas são motivadas por diversos fatores para produzirem se preocupando com questões ambientais, tais como exigência do mercado, pressão da sociedade e por cumprimento de leis. Em relação à exigência de mercado, a consciência ecológica e social gera oportunidades de negócios, consumidores de outros países procuram produtos de empresas que buscam se adequarem a questões ambientais e humanas, grupos que integram a sociedade local reforçam a cobrança de novas formas de atuação cobrando ações e informações relativas ao meio ambiente, instituições financeiras, por exemplo, requisitam relatórios de impactos ambientais e projetos que diminuem as consequências negativas na natureza para depois liberarem os recursos a serem financiados, as seguradoras pressionam as empresas para aperfeiçoarem os modelos de gestão, os acionistas demonstram preocupação quanto a tomada de decisão que diminuem os impactos ambientais, as ONGs representadas pelos ambientalistas buscam solucionar os problemas ambientais levando as empresas a repensar sobre fatores ambientais chamando a atenção da sociedade para formarem opiniões e pressionarem as autoridades responsáveis, os empregados quando esclarecidos de que a empresa pode afetar a qualidade de vida, exige uma postura diferente que beneficiem o bemestar social. Outro fator que pode mudar a consciência da empresa é a obrigação de se adequar a leis ambientais para evitar possíveis penas ou interferências na licença de funcionamento (MACHADO; DE OLIVEIRA, 2009).

Alisson (2013) descreve que, o projeto idealizado por Francisco Luiz Biazini Filho e desenvolvido pelo Centro de Inovação, Empreendedorismo e Tecnologia (Cietec), com apoio do Programa FAPESP Pesquisa Inovativa em Pequenas Empresas (PIPE), originou um sistema que atende às normas da Política Nacional de Resíduos Sólidos (PNRS) que estabelece aos fabricantes, importadores, distribuidores e comerciantes de produtos em geral a criação de um sistema de logística que possibilite reciclar os materiais por eles gerados. O projeto denominado "Rede Resíduo" aproxima grandes geradores de resíduos com recicladores, transportadores e 
empresas de tratamento e disposição final, através de uma plataforma do sistema Ciclo, disponibilizada em rede virtual, onde os geradores podem vender, trocar, doar ou destinar seus resíduos em uma espécie de bolsa de mercadorias e serviços que torna o que seria um problema, um negócio lucrativo e ambientalmente correto, pois o que seria descartado como lixo por uma empresa, passa a ser um insumo importante para outra. Esta inovação na gestão de resíduos atende às exigências da nova legislação e ao mesmo tempo obtêm receitas ou reduzem as despesas.

De acordo com a Lei $n^{\circ} 12.305$ de 2010, que institui a Política Nacional de Resíduos Sólidos (PNRS), os resíduos sólidos são materiais, substâncias ou objetos resultantes de atividades humanas em sociedade cujas particularidades tornem inviável o seu lançamento na rede pública de esgotos ou em corpos d'água. O controle destes resíduos permite o avanço necessário ao país no enfrentamento dos principais problemas ambientais, sociais e econômicos, além de ajudar o Brasil a atingir a meta de reciclagem de resíduos que é de $20 \%$ do total até o ano de 2015 (BRASIL, 2010).

Resíduos industriais são resíduos que sobram das atividades dos diversos ramos da indústria, como por exemplo: cinzas, lodos, plásticos, papel, madeira, borracha, retalhos de couro, etc. A gestão de resíduos sólidos é formada por várias ações ou procedimentos que visam reduzir ou eliminar os impactos ambientais provocados pelos resíduos oriundos das diversas atividades econômicas para propiciar melhor qualidade de vida, de saúde e do bem estar social. Uma empresa que desenvolve uma boa gestão poupa matériasprimas, economiza energia e preserva o meio ambiente (SOUZA; ALMEIDA; SANTOS, 2013).

\section{Procedimentos Metodológicos}

O tipo de pesquisa foi descritivo, para que não ocorresse interferência nos processos tampouco nos resultados. Nunes (2012) descreve que pesquisa descritiva é a realização de estudo, análise, registro e interpretação dos fatos em que o pesquisador não interfere na pesquisa.

Um dos pontos centrais desta pesquisa foi o uso de dados que ocorrem naturalmente, procurando conhecer os fatos e as consequências para os indivíduos, utilizando a forma de abordagem qualitativa. Para Silverman (2009) a forma de abordagem qualitativa procura conhecer os fenômenos sociais indisponíveis em qualquer lugar. Segundo Baptista e Campos (2010) a forma de abordagem qualitativa diferencia-se da forma de abordagem quantitativa pelo aspecto de abordagem dos dados, pois não levam em conta os números, mas sim foco no alvo principal da análise, mesmo que possa haver variações que não sejam abordadas durante a pesquisa.

O procedimento técnico adotado foi 
estudo de caso. Para Yin (2005) estudo de caso é um procedimento de pesquisa que incorpora abordagens importantes como coleta e análise de dados tornando-se uma estratégia de pesquisa muito mais abrangente, permitindo ao pesquisador estudar um caso ou vários casos simultaneamente através da investigação direta na fonte.

A técnica de coleta de dados envolveu entrevista, observação, documentos e registro de arquivos. Para Lakatos (2003) a técnica de coleta de dados é mais uma etapa da pesquisa cientifica que requer do pesquisador cuidados na prática de coleta das informações e exige empenho e planejamento estratégico para não perder mais tempo do que o necessário evitando erros e informações falsas durante a pesquisa.

A entrevista, de acordo com Lakatos (1992) é conversa realizada pessoalmente com o entrevistado seguindo os critérios metodológicos para retirar informações consideradas importantes para o trabalho a ser realizado. A entrevista foi realizada com o gerente geral (supervisor) que trabalha há 20 anos na empresa. Ainda segundo Lakatos (1992) a técnica de coleta de dados tipo observação usa os sentidos para obter informações reais, não se caracterizando apenas em ver e ouvir, mas também examinar fatos ou fenômenos que se pretende estudar. $\mathrm{O}$ período de observação da produção foi de três meses.

Para Moretti (2008) a técnica de coleta de dados em documentos e arquivos é baseada em investigação de documentos com a finalidade de descrever e comparar usos, costumes e tendências focando sempre a realidade atual. Foram analisados os documentos de controle de estoque e registros de notas fiscais de vendas dos resíduos sólidos descartados efetuadas as empresas que compram o material para outra destinação.

A técnica de análise dos dados foi análise de conteúdo para facilitar o entendimento dos resultados apresentados. Para Baptista e Campos (2010) a análise de conteúdo como tratamento dos dados caracteriza-se como um instrumento metodológico que contribui para facilitação do entendimento dos relatos do indivíduo, possibilitando de modo subjetivo compreender o verdadeiro significado do relato, não esquecendo que o homem é um agente que influencia ou pode ser influenciado pelo meio em que ele esta inserido.

\section{Resultados e Análise}

Os resultados descritos neste artigo foram coletados em um estudo de caso realizado na Fábrica de Calçados Kebec Boots, empresa instalada no município de ParanaíbaMS, que atua no ramo calçadista há 20 anos. A entrevista foi realizada junto ao gerente geral (supervisor) que trabalha há 20 anos na empresa. O mercado de atuação da empresa é em todo o mercado interno, incluindo o abastecimento da loja da fábrica e de todas as 
lojas da empresa distribuídas no estado de Mato Grosso do Sul.

Os processos de produção que são realizados na empresa são separados em setores distintos para facilitar o processamento, sendo eles: Design/modelagem; Corte; Pesponto (costura), Injetado e Montagem/Acabamento. Paralelamente ao setor de Injetado há o setor de preparação de sola pneu. No design/modelagem são realizados os projetos de calçados e idealizados novos modelos, novas linhas e coleções. No setor de corte são realizados os cortes dos couros e couros sintéticos com auxílio de facas e balancins, os cabedais possuem várias peças de diversos tamanhos e numerações diferentes.

No setor de costura/pesponto após receber as peças do setor de corte são costuradas e preparadas, os cabedais e as demais peças são costuradas, picotadas, coladas e dependendo do modelo são incrementados enfeites, fivelas, bordados $\mathrm{e}$ outras aplicações. No setor de injetados são produzidas as solas de pvc e látex com auxílio de máquinas injetoras que através de matrizes (formas) injetam o solado com número específico. Junto a este setor há o setor de preparação de sola pneu que também é injetada porém é adquirida de outra empresa, apenas necessita de preparação como lixação e limpeza. $\mathrm{Na}$ montagem/acabamento os montadores com auxilio de formas unem os cabedais já costurados com a sola do mesmo número e incluem biqueiras, contrafortes e palmilhas. No final do processo de montagem é realizado o processo de acabamento onde se realiza a limpeza, enceramento, revisão e encaixotamento.

Define-se que os resíduos sólidos mais comuns que sobram dos processos produtivos de uma indústria calçadista são: no setor de corte: retalhos de couro e aparas de couro; no setor de costura (pesponto): restos de linhas e aparas de couro; no setor de montagem / acabamento: caixas de papelão estragadas, latas de alumínio e pó de coletor, no setor de injetados: solas com defeitos e retalhos de PVC (Poli Cloreto de Vinila), e na preparação de sola pneu; pó de coletor. Os retalhos de couro são revisados e alguns são reutilizados pela empresa no corte de cabedais infantis, assim o que não é reutilizado é considerado descarte e possui outro destino. A responsabilidade quanto ao tratamento destes resíduos é de quem gera, devendo a empresa encontrar a melhor solução para minimizar impactos ambientais (LIMA, 2009). Os resíduos mais comuns no processo produtivo da empresa são apresentados na Tabela 1: 
Tabela 1: Resíduos sólidos mais comuns no processo produtivo da empresa

\begin{tabular}{|l|c|c|c|}
\hline \multicolumn{1}{|c|}{ Resíduos mais comuns } & Quantidade / mês & $\begin{array}{c}\text { Formas de } \\
\text { Armazenagem }\end{array}$ & Destinação \\
\hline Retalhos de couro & $180 / 200 \mathrm{~kg}$ & Sacos plásticos & Venda \\
\hline Restos de linhas & Não informado & Tambores & Lixão \\
\hline Aparas de de couro & Não informado & Tambores \\
\hline Papelão & Não informado & Empilhados & Coleta seletiva \\
\hline Pó de sola (coletor) & $100 \mathrm{~kg}$ & Tambores & Lixão \\
\hline Solas de pvc com defeitos & $200 \mathrm{~kg}$ & Sacos plásticos & Triturada e reutilizada \\
\hline Retalhos de pvc & $300 \mathrm{~kg}$ & Sacos plásticos & Triturados e reutilizados \\
\hline Embalagens plásticas & Não informado & Tambores & Coleta seletiva \\
\hline
\end{tabular}

Da destinação final dos resíduos produzidos pela indústria estudada, $100 \%$ dos retalhos de couro são vendidos para o frigorífico do grupo Marfrig, os restos de linhas, as aparas de couro e o pó de coletor são enviados para o lixão, as solas com defeito e os retalhos de pvc do setor de injetados, são triturados e reutilizados pela empresa e voltam para o processo de produção, as caixas de papelão estragadas, os plásticos e as latas de alumínio são armazenados em tambores e são recolhidos semanalmente pela COOREPA (Cooperativa Recicla Paranaíba). Empresas que desenvolvem uma boa gestão reaproveitam matérias-primas economizam energia e preservam o meio ambiente (SOUZA; ALMEIDA; SANTOS, 2013).

A empresa onde o estudo foi realizado está ciente dos possíveis danos que ela pode causar ao meio ambiente e para evitá-los, adota algumas medidas que estão contribuindo para a preservação do ambiente natural. Existem orientações aos colaboradores para a redução da geração de resíduos sólidos, pois todo consumo gera desperdício e a redução contribui para a preservação ambiental e trás benefícios econômicos para empresa. As ações pedagógicas da educação ambiental também são consideradas essenciais como meio de conscientização quanto à necessidade de minizar o desperdício de materiais (BALDIN; ORTH; ZANOTELLI, 2014).

Foi constatado que o resíduo produzido em maior volume são os retalhos de couro do setor de corte e estes são vendidos na sua totalidade para o grupo Marfrig que utiliza os retalhos de couro para limpeza e esterilização dos ganchos em que são pendurados os bovinos. As solas com defeitos e os retalhos de pvc que sobram do setor de injetados são triturados e reinseridos no processo de fabricação de solas injetadas. As caixas de papelão, os plásticos e as latas de alumínio são armazenados em tambores, pois uma vez na semana a COOREPA realiza a coleta seletiva. $\mathrm{O}$ adequado gerenciamento dos resíduos sólidos considerando a redução na geração e a conversão em matéria-prima, coopera na redução dos custos de operação (COELHO et al, 2011). A Kebec compra a sola pneu de outra empresa para a fabricação de alguns modelos de calçados, este solado é considerado um material ecologicamente correto, pois é originário de pneus reciclados. 
Identificou-se um ponto negativo em relação à destinação correta de alguns resíduos, tipo: retalhos de linhas, aparas de couro e pó de coletor, pois não são reutilizados pela empresa, não fazem parte da coleta seletiva e não são vendidos, sendo o único destino o lixão. $\mathrm{O}$ aumento da produção e a falta de programas eficazes de gestão acarretam na sobrecarga de resíduos que não são devidamente reutilizados comprometendo a qualidade de vida de gerações futuras. Como o município ainda não conta com um aterro sanitário não é viável o descarte destes resíduos no lixão, pois ao longo dos processos foram sendo aplicados solventes, halogênios e colas adesivas adotando características de periculosidade por serem tóxicos, em especial as aparas de couro que também são provenientes de couros curtidos ao cromo que é um mineral tóxico. Grande parte destes resíduos afetam negativamente o meio ambiente visto que contém elementos que prejudicam a saúde humana e ainda podem contaminar o solo e os lençóis freáticos (RIBEIRO; MORELLI, 2009).

Neste contexto Alisson (2013) expõe que seria interessante uma instituição que aproximasse os grandes geradores de resíduos com recicladores, transportadores e empresas de tratamento e disposição final, por meio de uma plataforma do sistema ciclo, disponibilizada em rede virtual, em que os geradores podem vender, trocar, doar ou destinar seus resíduos em uma espécie de bolsa de mercadorias e serviços que torna o que seria um problema, um negócio lucrativo e ambientalmente correto.

\section{Considerações Finais}

Este estudo teve como objetivo analisar a gestão de resíduos sólidos industriais no processo produtivo de uma indústria calçadista. De acordo com a pesquisa constatou-se que a empresa onde o estudo foi realizado está ciente dos possíveis danos que ela pode causar ao meio ambiente e para evitálos, adota algumas medidas que estão contribuindo para a preservação ambiental. Existem orientações aos colaboradores para a redução da geração de resíduos sólidos, deixando-os cientes de que todo consumo gera desperdício e a redução contribui para a preservação ambiental e trás benefícios econômicos para empresa.

O resíduo mais comum na empresa é o retalho de couro que possui atenção especial, pois, após o corte da matéria prima o retalho é reutilizado em cabedais infantis e só depois é armazenado e repassado para outra empresa, desta forma o que não é reaproveitado é vendido propiciando mais receitas. Os restos de linhas, as aparas de couro e o pó de coletor são enviados para o lixão, tornando o maior problema para a empresa quando o assunto é gestão de resíduos sólidos, pois, não há interessados na compra destes resíduos e a falta de um aterro sanitário contribui para a degradação do ambiente natural.

A adequada gestão de resíduos sólidos é observada no tratamento das solas com 
defeito e dos retalhos de PVC do setor de injetados, pois, são triturados e reutilizados pela empresa e voltam para o processo de produção, as caixas de papelão estragadas, os plásticos e as latas de alumínio são armazenados em tambores e são recolhidos semanalmente pela COOREPA, cooperativa parceira da empresa que realiza a coleta seletiva semanalmente.

Destarte, a pesquisa demonstrou como é a gestão de resíduos sólidos da industria Kebec no município de Paranaíba-MS, e demonstrando assim a importância do estudo para preservação ambiental e sua adequação legais frente ao Plano Nacional de Resíduos Sólidos, verifica-se tambem a necessidade de estratégias que propicie a empresa não apenas fins lucrativos, mas ambientalmente sustentáveis, além de reduzir os impactos ambientais. De acordo com o trabalho apresentado pode-se concluir que é necessário que durante $\mathrm{o}$ processo produtivo a sustentabilidade faça parte do cotidiano das empresas evitando assim que os problemas ambienais se tornem irreversíveis.

\section{Referências}

\section{ABICALÇADOS. Perfil da indústria} nacional. Disponível em:

$<$ http://www.abicalcados.com.br/site/abicalcad os.php?id=5>. Acesso em 16 jun 2015.

ABNT, Associação Brasileira de Normas Técnicas. NBR 10004. Resíduos sólidos Classificação. Rio de Janeiro, 2004.

\section{ALISSON, E. Rede possibilita que empresas} façam gestão de resíduos. Agência FAPESP, 2013. Disponível em:
$<$ http://www.agencia.fapesp.br/16670>. Acesso em: 30 abr. 2014.

BALDIN, N.; ORTH, C. M.; ZANOTELLI, C. T. A geração de resíduos sólidos em um processo produtivo de uma indústria automobilística: uma contribuição para a redução. Gestão \& Produção, São Carlos, v. 21, n. 2, Jun., 2014.

\section{BAPTISTA, M. N. Metodologias de pesquisa} em ciência: análises quantitativas e qualitativa. Rio de Janeiro: LTC, 2010

\section{BRASIL. Lei 12.305, de 02 de agosto de}

2010. Institui a Política Nacional de Resíduos Sólidos; altera a Lei no 9.605, de 12 de fevereiro de 1998; e dá outras providências. Disponível em:

$<$ http://www.planalto.gov.br/ccivil_03/_ato20 07-2010/2010/lei/112305.htm>. Acesso em: 20 abr. 2014.

COELHO, H. M. G. et al . Proposta de um Índice de Destinação de Resíduos Sólidos Industriais. Engenharia Sanitária e

Ambiental. Rio de Janeiro, v. 16, n. 3, Set. 2011.

DIAS, R. Gestão ambiental: responsabilidade social e sustentabilidade. São Paulo: Atlas, 2007.

\section{FAPESP. Reaproveitamento de resíduos} sólidos classe 1 de couros em semiacabado e acabado de diferentes raças (bovinas, suínas, de peixe, de jacaré, de avestruz, de cavalos, de cabras e de ovelhas). Disponível em:

$<$ http://www.bv.fap-

esp.br/pt/bolsas/123701/reaproveitamentoresíduos-classe1/>. Acesso em 02 jun. 2013.

FRACASSO, E. M.; VIEGAS, C. Capacidade tecnológica e gestão de resíduos em empresas de calçados do Vale do Sinos: estudo de dois casos. Revista de Administração Contemporânea., Curitiba, v. 2, n. 2, Ago. 1998.

\section{LAKATOS, E. M. Fundamentos de} metodologia científica. 5. ed. São Paulo: Atlas, 2003. 
LAKATOS, E. M. Metodologia do trabalho científico: procedimentos básicos, pesquisa bibliográfica, projeto e relatório, publicações e trabalhos científicos. 4. ed. São Paulo: Atlas. 1992.

LIMA, R. S. Gestão dos resíduos sólidos. São Paulo: Pearson Education do Brasil, 2009.

MACHADO, A. G. C., DE OLIVEIRA, R. L. Gestão ambiental corporativa: Pressões em prol da gestão ambiental empresarial. In: ALBUQUERQUE, J. L. (Org). Gestão Ambiental e Responsabilidade Social: Conceitos, Ferramentas e Aplicações. São Paulo: Atlas, 2009. P. 96-99.

MORETTI, N. Manual de metodologia científica: como elaborar trabalhos acadêmicos. Disponível em. $<$ http://pt.scribd.com/doc/19441613/Manualde-Metodologi-a-Cientifica $>$. Acesso em 10 jun. 2013.

NUNES, A. S. As diferenças entre as pesquisas exploratórias, descritivas e explicativas. Disponível em:

$<$ http://www.posgraduando.com/guia/asdiferencas-entre-as-pesquisas-exploratoriadescritiva-e-explicativa $>$. Acesso em 09 junho 2013.

RIBEIRO, D. V., MORELLI, M. R. Resíduos Sólidos: problema ou oportunidade? Rio de Janeiro: Interciência, 2009.

SILVERMAN, D. Interpretação de dados qualitativos: métodos para análise de entrevistas, textos e interações. Porto Alegre: Artmed, 2009.

SOUZA, P. S. S.; ALMEIDA, P. L. P.; SANTOS, S. F. M. Gestão Ambiental: um estudo sobre o gerenciamento dos resíduos sólidos de uma indústria de embalagens flexíveis em Campina Grande-PB. X SIMPÓSIO DE EXCELÊNCIA EM GESTÃO E TECNOLOGIA. Anais... Disponível em: $<$ http://www.aedb.br/seget/arquivos/artigos09/ 257_Gestao_Ambiental.pdf $>$. Acesso em 30 abr 2013.
SUZUKI, R. L. Gestão dos resíduos sólidos. São Paulo: Pearson Education do Brasil, 2009.

YIN, R. K. Estudo de caso: planejamento e métodos. 3. ed. Porto Alegre: Bookman, 2005. 